\title{
Literacy Challenges for the Twenty-First Century: Introducing the Issue
}

\section{Citation}

Murnane, Richard, Isabel Sawhill, and Catherine Snow. 2012. "Literacy Challenges for the Twenty-First Century: Introducing the Issue." The Future of Children 22 (2): 3-15. doi:10.1353/ foc.2012.0013.

\section{Published Version}

doi:10.1353/foc. 2012.0013

\section{Permanent link}

http://nrs.harvard.edu/urn-3:HUL.InstRepos:34785395

\section{Terms of Use}

This article was downloaded from Harvard University's DASH repository, and is made available under the terms and conditions applicable to Open Access Policy Articles, as set forth at http:// nrs.harvard.edu/urn-3:HUL.InstRepos:dash.current.terms-of-use\#OAP

\section{Share Your Story}

The Harvard community has made this article openly available.

Please share how this access benefits you. Submit a story.

\section{Accessibility}




\section{Literacy Challenges for the Twenty-First Century: Introducing the Issue}

\section{Richard Murnane, Isabel Sawhill, and Catherine Snow}

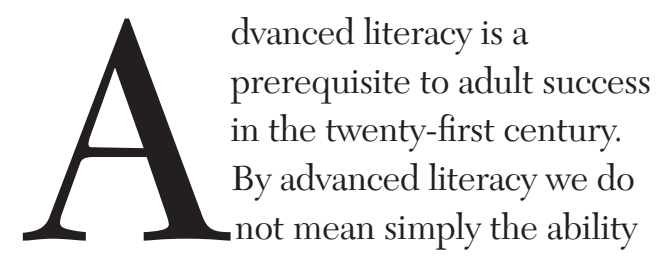

to decode words or read a text, as necessary as these elementary skills are. Instead we mean the ability to use reading to gain access to the world of knowledge, to synthesize information from different sources, to evaluate arguments, and to learn totally new subjects. These higher-level skills are now essential to young Americans who wish to explore fields as disparate as history, science, and mathematics; to succeed in postsecondary education, whether vocational or academic; to earn a decent living in the knowledge-based globalized labor market; and to participate in a democracy facing complex problems.

The literacy challenge confronting children, their families, and schools in the United States has two parts. The first is the universal need to better prepare students for twentyfirst-century literacy demands. The second is the specific need to reduce the disparities in literacy outcomes between children from disadvantaged backgrounds and those from more privileged homes.
This issue of the Future of Children explores the literacy of America's children and how to improve it. We begin this introductory essay by reviewing briefly why literacy is so important in today's world and why the concept of literacy needs to be broadened to include a set of competencies that go well beyond the ability to recognize words and decode text. We end with a summary of the other articles in the issue and briefly consider what steps policy makers might take to respond to the urgent needs we cite.

\section{The Growing Demand for Strong Literacy Skills}

The "literacy problem" we address here is not that literacy has declined among recent generations of children. It is that today's economy and the complex political and social challenges facing the nation demand more advanced skills than ever before.

The average reading skill of non-Hispanic white children from recent cohorts is remarkably similar to that of comparable children born in the 1960s, and the average reading achievement of recent cohorts of black children and Hispanic children is considerably higher than that of comparable

Richard Murnane is the Thompson Professor of Education and Society at the Harvard Graduate School of Education; Isabel Sawhill is a senior fellow, Cabot Family Chair, and co-director of the Center on Children and Families, at the Brookings Institution; Catherine Snow is the Patricia Albjerg Graham Professor of Education at the Harvard Graduate School of Education. 
Figure 1. National Assessment of Educational Progress Test Score Trends in Reading: National Averages for Thirteen-Year-Olds (Eighth Grade)

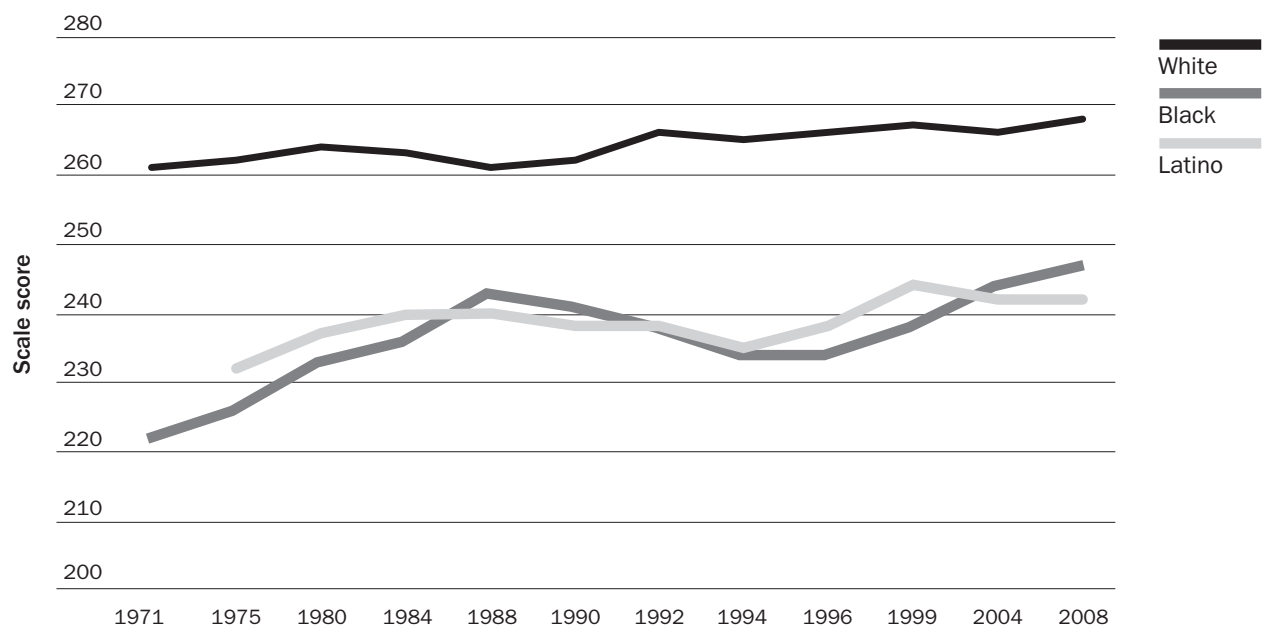

Source: U.S. Department of Education, Institute of Education Sciences, National Center for Education Statistics, National Assessment of Educational Progress (NAEP), various years, 1971-2008 Long-Term Trend Reading Assessments.

cohorts born several decades ago. These points are illustrated in figure 1 , which presents trends from the National Assessment of Educational Progress in the average reading levels of American thirteen-year-olds in the major race and ethnicity groups.

Although the literacy of American children has not changed appreciably over the past forty years, the American labor market has changed dramatically. The change in the nation's occupational structure is illustrated in figure 2 , which displays the shares of workers employed in large occupational groups, arrayed from lowest wage on the left to highest wage on the right. The big declines between 1979 and 2009 in the share of workers employed in particular occupations took place in blue-collar jobs (for example, assembly line work) and administrative support (for example, filing). These jobs require workers who can read, but historically they have not demanded advanced literacy skills. Jobs have declined in these occupations because they can be and have been taken over by computer-guided machines or by workers in lower-wage countries. ${ }^{1}$

During those same three decades the demand for workers in higher-paid occupations, for example, in technical and professional fields, was growing. These jobs typically require postsecondary education or training, leaving workers with inadequate literacy skills competing for the growing number of low-paying service jobs.

Americans also need strong literacy skills to participate constructively in a pluralistic democracy facing complex domestic and global challenges, including a large national debt, global warming, and the proliferation of nuclear weapons. There is no shortage of information about these challenges. Indeed, Internet searches turn up thousands of documents and opinions on every one. But sifting through the conflicting arguments and judging which pieces of evidence hold up to 
scrutiny require significant literacy skills. The nation's ability to meet these challenges is quite likely to depend on the extent to which the electorate understands them.

Another new challenge is the changing demographic composition of the nation's children.

As shown in figure 3, the share of the nation's children who are non-Hispanic whites is declining, while the share of Hispanic children is growing rapidly, and the share of black children is holding relatively constant. As a result, within the next thirty years, Hispanic and black children in the United States will outnumber non-Hispanic white children. As illustrated in figure 1, the literacy skills of Hispanic and black children are significantly lower, on average, than those of non-Hispanic white children. Unless the United States can markedly improve the literacy skills of today's minority children the labor force of the future will have lower literacy skills than the labor force of today.

\section{Large and Growing Gaps in Literacy Skills by Socioeconomic Status}

As noted, our concern in this issue is not only the overall literacy skills of American students, but also the gaps between more and less advantaged children. The disparities associated with family income have grown markedly over the past half century. Among children born during the 1940s, the gap between the average reading achievement of those growing up in families at the 10th percentile of the income distribution and those growing up in families at the 90th percentile of the income distribution was about 0.60 standard deviation. Among cohorts born in the first years of the twenty-first century, the corresponding gap in average reading skills is twice as large, about 1.25 standard deviations. That pattern, documented by sociologist Sean Reardon ${ }^{2}$ and illustrated in figure 3 of the article he and his colleagues wrote for this issue, is extremely troubling.

Figure 2. The Adult Occupational Distribution: 1979 and 2009

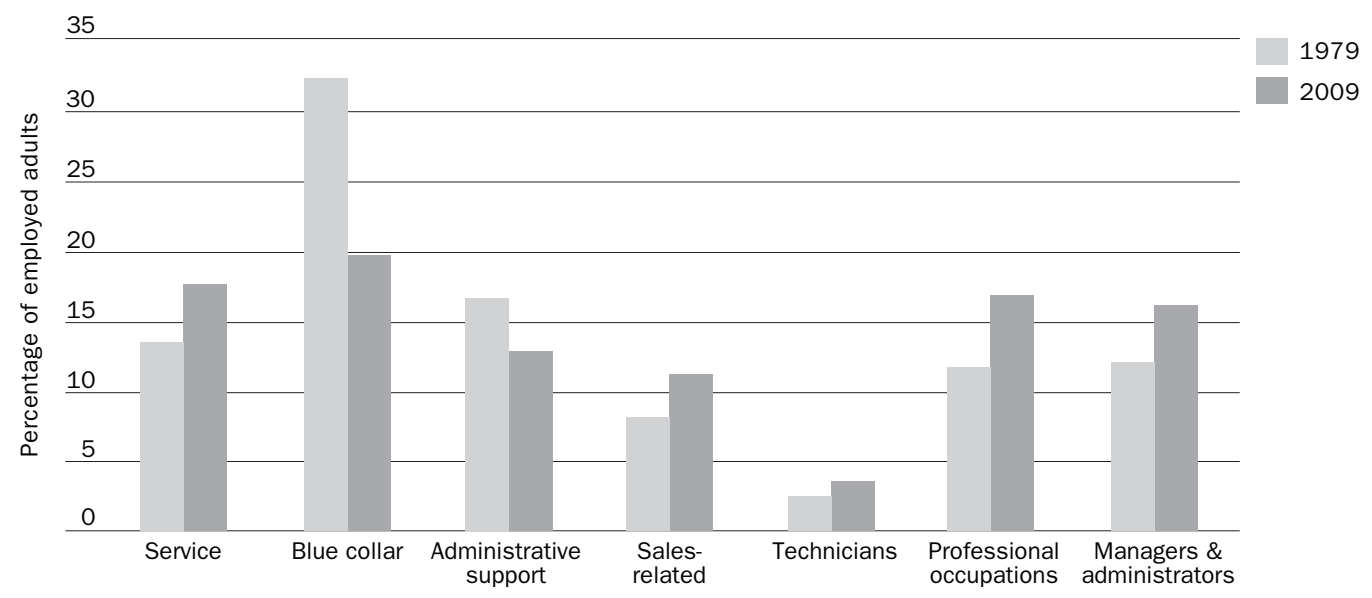

Source: Authors, based on tabulations of data from the Current Population Survey provided by Professor David Autor of MIT. Note: The data include all persons aged 16-64 who reported having worked last year, excluding those employed by the military and in agricultural occupations. 
High rates of intergenerational mobility have always been central to the distinctively American belief in opportunity, and education is the primary mechanism driving upward mobility. Low literacy levels among children from less advantaged families dramatically reduce the potential for upward mobility. Preliminary results from the Brookings Institution Social Genome Model show that if the academic success rates of lower- and higher-income children were roughly equal at the end of elementary school, the lifetime incomes of children from lower-income families could grow about 8 percent, or roughly $\$ 83,000$, over their careers. ${ }^{3}$

\section{Literacy Development: It's Not Just Decoding and Summarizing Anymore}

If success in the twenty-first century depends increasingly on advanced literacy skills and the education and training they make possible, it is important for educators, policy makers, and the public to understand what advanced literacy is. In short, a new definition of literacy is required — one that highlights the skills that children need to deal with the new demands.

Widely used assessments of reading comprehension typically treat it as a relatively shallow process — one that involves being able to

Figure 3. Percentage of Children Aged 0-17 in the United States by Race and Hispanic Origin, 1980-2010 and Projected 2011-50.

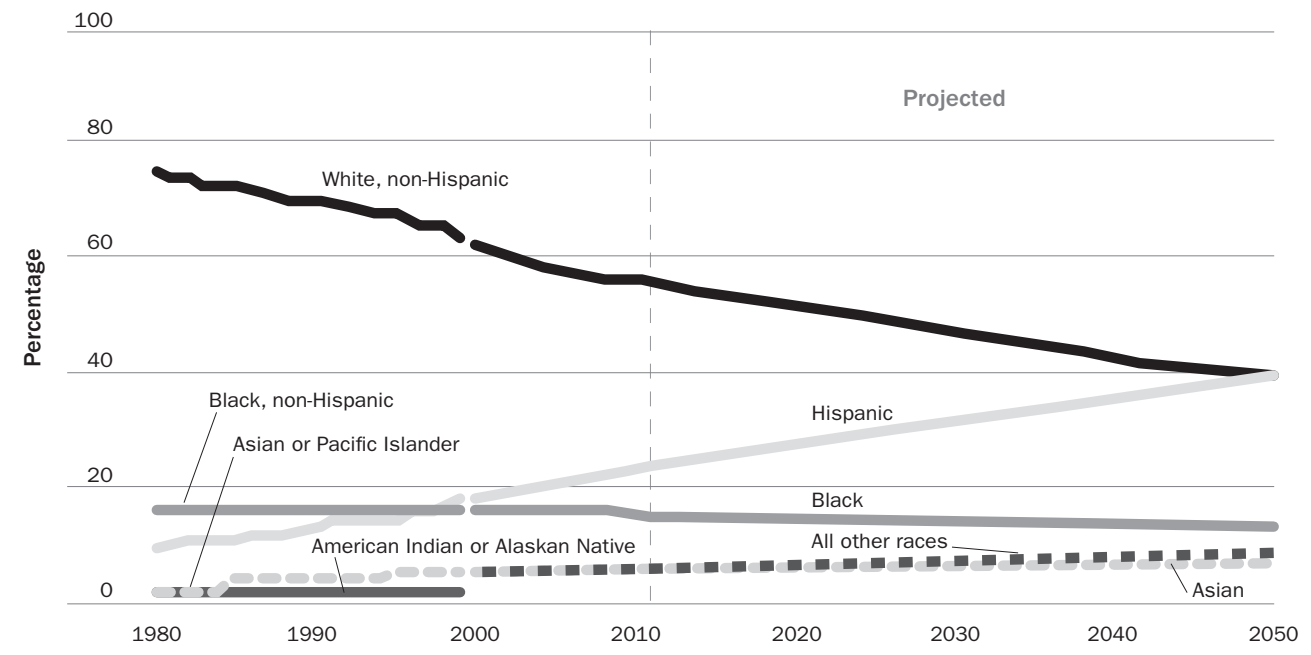

Source: U.S. Census Bureau, Population Estimates and Projections, as found at: www.childstats.gov/americaschildren/demo .asp\#figure1. Data from 2000 onward are not directly comparable with data from earlier years. Data on race and Hispanic origin are collected separately; Hispanics may be any race. In 1980 and 1990, following the 1977 Office of Management and Budget (OMB) standards for collecting and presenting data on race, the decennial census gave respondents the option to identify with one race from the following: White, Black, American Indian or Alaskan Native, or Asian or Pacific Islander. The Census Bureau also offered an "Other" category. Beginning in 2000, following the 1997 OMB standards for collecting and presenting data on race, the decennial census gave respondents the option to identify with one or more races from the following: White, Black, Asian, American Indian or Alaska Native, and Native Hawaiian or Other Pacific Islander. In addition, a "Some other race" category was included with OMB approval. Those who chose more than one race were classified as "Two or more races." Except for the "All other races" category, all race groups discussed from 2000 onward refer to people who indicated only one racial identity. (Those who were "Two or more races" were included in the "All other races" category, along with American Indians or Alaska Natives and Native Hawaiians or Other Pacific Islanders.) 
remember (or quickly find) information read, to summarize a paragraph, to identify the main idea of a paragraph, and perhaps to make simple inferences from information in the text. These assessments typically require reading a series of brief texts and responding to multiple-choice questions based on them or perhaps selecting appropriate words to fill in blanks in the text. Assessments designed to tap the skills that are directly relevant to academic success and to workplace demands require students to synthesize information across different sources, to evaluate arguments on a variety of dimensions, to understand varying perspectives on an issue, and to assess the credibility of sources of informationskills that we will call "deep comprehension."

Much literacy instruction in U.S. schools is guided, implicitly or explicitly, by "the simple view" of reading. ${ }^{4}$ According to this view, reading comprehension depends on accuracy and speed of word reading and on oral understanding of the words to be read. The simple view has had the salutary effect of ensuring that educators recognize the need to include language as well as word reading in early reading instruction. The utility of the simple view declines, though, as the tasks used to tap comprehension become more authentic and more challenging. The simple view does an excellent job of explaining comprehension of the sort that enables a young reader to answer multiple-choice questions about relatively brief and effectively neutral texts. But it is less adequate in reflecting deep comprehension skills - those needed for reading to learn, to synthesize, to analyze, and to critique.

The simple view does not, for example, direct much attention to issues of background knowledge. Schema theories of reading comprehension represent reading comprehension as a process of updating a reader's knowledge schemas by integrating information encountered in text with information already stored. ${ }^{5}$ If the newly encountered information confirms what is stored in memory, then the reader can comprehend it with ease. If the new information conflicts with that stored in memory, then the reader needs to analyze it for correctness, or at least for credibility, and decide whether to update his or her schema. If the new information agrees with that stored in memory, perhaps extending it, then the reader can learn it relatively easily by updating his or her schema.

Comprehension challenges rise when the text deals with information unconnected to any existing schema in the reader's knowledge base. Such information is a challenge for developing readers and continues to be an obstacle for mature, skilled readers.

Americans struggle to understand newspaper reports of cricket matches, just as British sports fans do with reports of baseball games. The schemas on which to hang descriptions of runs, innings, outs, and points are specific to the two games and constitute the background required for comprehension.

Ironically, then, one of the most important inputs to successful reading comprehension is knowledge, some of it acquired without reading at all. One major difference between children likely to become good readers and those likely to struggle is vocabulary knowledge. As early as age three, middle-class and disadvantaged children display enormous differences in the size of their vocabulary, because they have had differing experiences with conversations from which they can learn new things. ${ }^{6}$ Vocabulary is a convenient index of breadth of knowledge. Knowledge creates the framework on which reading comprehension builds. 


\section{Literacy Instruction: The Ideal and the Real}

Excellent reading instruction, then, balances attention to the skills required for accurate and fluent word reading with opportunities to expand students' knowledge and language. Ideally, both these goals are kept in mind at every stage of instruction. In far too many U.S. classrooms, though, attention to language and to knowledge building is severely diminished starting in kindergarten, when letters, then letter-sound pairings, then word reading absorb all the instructional attention.

\section{Preschool}

Good early childhood education provides opportunities to learn emergent literacy skills-to identify letters, to recognize frequently encountered words like "stop" or "exit," to write one's own name, to know what sounds the initial letters of a word represent, to rhyme, to use knowledge of letter names and letter sounds to produce invented spellings. Reading aloud is often incorporated by teachers into this emergent literacy agenda and is used as an opportunity to point out words and letters in meaningful contexts.

The value of these emergent literacy activities is undeniable. They predict children's skills at kindergarten entry, and children who do better at letter recognition, phonological awareness tasks, and reading words as fiveyear-olds are very likely to have an easier time learning to read. Children of low-income families are more likely to spend time in under-resourced and informal child care settings (see the article by Jane Waldfogel), where they have less access to these activities and where they miss opportunities to help them catch up to their middle-class peers.

Children from families with more financial and cultural resources differ from their less advantaged peers, though, not just in knowledge of these early literacy skills but also in access to knowledge about topics related to the natural world (bugs, flowers, tidal pools), to astronomy (what shape the world is, why the sun sets), to current events (who the president is, what a mayor does, what a budget is), to history (why the Civil War was fought, who George Washington was), to human relations (how aunts and uncles are related to them, what divorce means). These differences are indexed by enormous social class differences in vocabulary and are produced by differential access to oral language interactions, exacerbated by differential access to engaging and language-rich books read aloud, both in the home and in early child care settings. Early childhood programs that provide such engaging and language-rich experiences do exist, and preschool practices focused on developing language and enriching knowledge have been shown to be effective. ${ }^{7}$ Unfortunately, they are not widespread.

\section{Primary Grades}

Literacy instruction in the primary grades of American schools is generally dominated by practices designed to ensure accurate and fluent decoding of grade-level texts by the end of grade three. Third-grade texts look like this:

It was a fine summer morning,

So Frances took out her bat and ball.

"Will you play ball with me?"

said her little sister, Gloria.

"No," said Frances.

"You are too little."

Gloria sat down and cried.

Frances walked over to her friend

Albert's house, singing a song:

Sisters that are much too small

To throw or catch or bat a ball

Are really not much good at all

Except for crying. ${ }^{8}$ 
Texts like this, however charming, offer little opportunity to grapple with deep comprehension. That is entirely appropriate because the technical challenges of reading English are sufficiently daunting that most students need lots of help and lots of practice to get good at it. Practicing deep comprehension while still struggling to decode multisyllabic words may simply be too hard.

On the other hand, children in the primary grades can practice some aspects of deep comprehension while listening to texts read aloud. They are capable of discussing and evaluating competing interpretations of a character's actions and competing explanations for physical phenomena. They are capable of integrating information from different sources, if they have access to those sources with the help of pictures, read-alouds, and videos, or help from better readers.

Observations suggest that primary-grade instruction devotes remarkably little time to science, civics, current events, or social studies, perhaps because of the accountability pressures to ensure that all students leave third grade reading at the third-grade level. Thus, children have the opportunity to learn reading as a tool, but the content that would support their later use of that tool for purposes of comprehension and further learning may be neglected.

\section{Middle Grades}

For most American students, ongoing literacy instruction takes place primarily in English language arts after third grade. In grades four and five, English language arts typically offers a variety of text genres and tasks, and students who are still having difficulty learning to read are likely to receive special help. The selfcontained classroom model that predominates through grade five facilitates flexible use of time and some level of attention to literacy across the curriculum.

During the transition to the departmentalized structure of grades six through eight, literacy instruction is severed from content instruction for many students. Excellent readers do not suffer under this regimen; they take the reading skills they have acquired, so far practiced predominantly on fiction in most cases, and adapt them to the reading of science and history textbooks. Well-informed students are also unlikely to suffer; they may already know, from dinner table conversations or from watching PBS and the History Channel, quite a bit about genetic inheritance, survival of the fittest, and the Civil War, so they have richly elaborated schemas on which to hang the new information to which their texts expose them.

But students with marginal reading skills, and good readers with limited knowledge stores, encounter new and often insurmountable tasks. No one teaches them how to read science or history, often because their history and science teachers are unaware of the degree to which the literacy demands of their texts deviate from those of books read earlier, but also because they do not know how to teach reading.

Researchers have devised and evaluated specific procedures that teachers can use to support the growth of reading skills in the postprimary grades. These procedures have in common helping students establish a purpose for reading, modeling how to work actively to understand text, providing strategies to support them in accessing the text, providing explicit instruction about differences in genres and discourse structures across different content areas, teaching crucial presupposed knowledge (vocabulary and information) before exposing students to the text, and 
requiring demonstrations of deep understanding (oral and written reports). The procedures have been packaged into various approaches, curricula, and programs. They have not been used as widely, or as well, as the nation requires.

\section{The Challenge and a Summary of the Articles in the Issue}

Given the economic demands, the educational challenges, and students' needs for twenty-first-century literacy skills, this issue explores what is known about current levels of literacy, their determinants, and new strategies to improve literacy.

\section{Trends in Literacy Levels and Gaps}

Sean Reardon, Rachel Valentino, and Kenneth Shores, all of Stanford University, provide a detailed look at how well U.S. students are performing. They find that about two-thirds of fourth graders, three-fourths of eighth graders, and three-fourths of twelfth graders were reading at a "basic" level in 2011. About one-third of students at each grade level were reading at a "proficient" level. Over the past forty years literacy skills scores on assessment tests have not improved much —in sharp contrast to sizable increases in math scores over this same period. The gaps in literacy skills by socioeconomic status and race are striking. Throughout elementary and middle school, girls consistently score about 0.2 standard deviation above boys; the black-white and Hispanic-white gaps are each about 0.6 standard deviation; and the income gap (10th vs. 90th percentile of family income) is larger still.

While the black-white and Hispanic-white gaps have narrowed somewhat over the past forty years, the socioeconomic gap has widened, and the gender gap has not changed. These gaps do not typically narrow as children progress through school. Indeed, they sometimes widen. For example, the blackwhite gap increases between kindergarten and third grade and widens further by eighth grade. U.S. scores are about, or a little above, average compared with those in other developed countries for similarly aged children. The authors conclude that literacy skills need to be improved. They take the narrowing of racial gaps in the past and the reasonable success schools have had in improving math skills as evidence that literacy skills are malleable.

\section{Nonschool Factors}

Because literacy gaps are present when children start school, nonschool factors such as families and communities must play a role in the acquisition of literacy skills and likely continue to exert an influence as children age. Jane Waldfogel, of Columbia University, uses the differences between subgroups (by race, socioeconomic status, and immigrant status) to tease out what these influences might be. She notes that parents are critical to children's early literacy. More advantaged parents are more responsive to their children, interact with them more frequently, and provide a richer learning environment through reading and other cognitively stimulating activities, such as use of a computer or visits to a library. Other factors playing a role in the acquisition of early literacy skills that vary with race or socioeconomic status include health and health-related behaviors and participation in preschool.

The reading gaps between black and white children are especially troubling because not only are they evident when children start school but they grow larger during the school years. In contrast, although Hispanic children start out behind (perhaps because of stilllimited English skills and lower levels of participation in preschool), the gaps with whites narrow or stabilize after a few years. A 
The reading gaps between

black and white children

are especially troubling

because not only are they

evident when children start

school but they grow larger

during the school years. In

contrast, although Hispanic

children start out behind, the

gaps with whites narrow or

stabilize after a few years.

variety of nonschool factors could be playing a role here, such as stronger families, less crime, or more positive peer group attitudes in Hispanic communities. Another possibility examined in this article is that differences in experiences over the summer for children from different backgrounds contribute to literacy gaps.

Waldfogel concludes that there is not one literacy problem but several different ones and that this complexity requires tailoring policy responses to these differences. For example, the early literacy of immigrant children tends to be influenced by their lack of English-language skills and the fact that English may not be spoken in the home. The literacy skills of black children and disadvantaged children are more likely to be affected by a lack of cognitively stimulating activities in the home or of other parenting practices that foster literacy and knowledge. Waldfogel also stresses, however, that out-of-school solutions are not the answer to out-of-school influences on literacy. Schools can and should address differences in literacy achievement, whatever their source.

\section{Progress over the Past Decade?}

In their article, Nell Duke, of the University of Michigan, and Meghan Block, of Michigan State University, describe key recommendations from a 1998 National Research Council report entitled Preventing Reading Difficulties in Young Children that were aimed at improving reading instruction in preschool to grade three in U.S. schools. The authors evaluate the extent to which U.S. elementary schools have adopted each of the recommendations and then review research on improving primary-grade reading conducted since the publication of Preventing Reading Difficulties. The authors conclude by describing obstacles that have hindered the adoption of several key recommendations of the report.

One conclusion is that reading instruction in the primary grades has moved to a greater emphasis on improving students' wordreading skills — the prerequisite to performing well on early literacy assessments-but that attention to developing children's comprehension, vocabulary, and conceptual knowledge has not increased. Yet these are the skills and knowledge essential to success in comprehending the material in subjectspecific texts in the upper elementary and middle school grades. Another important conclusion is that research conducted since Preventing Reading Difficulties was published provides considerable additional guidance regarding effective instructional practices.

The authors argue that three obstacles hinder improvement in reading instruction in the early elementary grades. The first is undue emphasis on word-reading skills in assessments 
of children's literacy skills in the early grades, which creates incentives for teachers to focus instruction on improving word-reading skills at the expense of the development of the vocabulary, comprehension skills, and conceptual knowledge that children need. The second is a lack of expertise among many educators on how to teach comprehension, conceptual knowledge, and vocabulary effectively. The third obstacle is insufficient time in the school day to teach effectively the vocabulary and conceptual knowledge that some English Language Learners and children from disadvantaged families do not learn outside of school.

\section{Improving the Literacy of Disadvantaged Children}

Nonie Lesaux, of Harvard University, describes what is known about reading development and reading instruction for children from low-income and non-English-speaking homes. She uses this research base to provide recommendations for educators and education leaders working to promote the literacy development of these two (often overlapping) academically vulnerable populations. Lesaux begins by explaining that reading is a dynamic and multifaceted process that requires continued development if students are to keep pace with the increasing demands of school texts and tasks. She explains that when reading effectively, readers not only decipher words on a page but also use their accumulating knowledge to assess, evaluate, and synthesize the presented information. She uses the term "skills-based competencies" to describe the skills children need to sound out and recognize words. She contrasts this concept with knowledge-based competencies that include the conceptual and vocabulary knowledge necessary to comprehend a text's meaning.
Lesaux echoes Duke and Block in explaining that U.S. schools have made considerable progress in teaching skills-based reading competencies, as reflected in improved scores on early reading assessments. However, the United States has made much less progress in teaching the knowledge-based competencies students need to support reading comprehension in the later grades. These competencies are key sources of lasting individual differences in reading outcomes, particularly among children growing up in low-income and non-English-speaking households. She suggests that by strengthening the language environments that are part of the everyday school experiences of students from nonEnglish-speaking or low-income homes, or both, educators can support children as they develop the knowledge-based competencies needed to access the school curriculum.

Providing such environments, Lesaux explains, requires considerable shifts in the way reading is assessed and taught in elementary and secondary schools. First, comprehensive reading assessment practices that discern learners' (potential) sources of reading difficulties-in both skills-based and knowledge-based competencies-are required. Second, she describes instructional approaches that offer promise for teaching the conceptual and knowledge-based reading competencies that are critical for academic success. Lesaux concludes that paying greater attention to sustained, comprehensive, and deep instruction, and using assessments that capture complex thinking and learning, will enable educators to augment students' literacy rates-particularly those of academically vulnerable populations.

\section{Literacy in the Subject Areas}

Susan Goldman, of the University of Illinois, focuses on what is known about using reading 
to learn content, the core educational task from fourth grade through high school. She describes what reading to learn content entails as well as the kinds of knowledge and conceptual skills needed for success at reading for learning. Goldman also explains that the literacy skills needed to acquire knowledge in one subject area, such as history, are quite different from those needed to acquire knowledge in other subject areas, such as biology. Goldman reviews the evidence on instructional interventions aimed at enabling students to acquire and gain proficiency at reading to learn.

A striking lesson from Goldman's article concerns the development of students' literacy skills in middle school and high school. For schools and teachers to assume that students possess the literacy skills needed to learn in the disciplines is a critical mistake. So is leaving to English teachers the task of building the skills of weak readers. Success in enabling students to acquire core knowledge in the disciplines requires teaching subject-specific literacy skills to many students. Currently, few subject-area teachers know how to do this or view it as a fundamental part of their job. Goldman concludes her paper with a brief discussion of what teachers need to know to support students in reading to learn.

\section{The Importance of Educational Infrastructure}

David Cohen and Monica Bhatt, both of the University of Michigan, discuss a variety of school-based initiatives and reforms that might address the literacy needs outlined in this issue. They note the existence of a generally accepted body of knowledge about reading instruction at least in the primary grades - but also discuss the organizational features of American schools that inhibit best practice. Although the accountability that has been introduced by standards-based reform has had some perverse effects, Cohen and Bhatt point out that it has helped to launch some potentially productive initiatives. These include comprehensive school reform designs and charter networks that build educational infrastructure (such as curriculum, professional development, quality control, and data use); programs to attract, reward, and promote better teachers; and perhaps the Common Core State Standards, a multistate initiative to set learning goals for reading/English language arts and mathematics at each grade level. Many challenges are involved in developing these standards and implementing them responsibly. However, if well-structured and well-resourced organizations like comprehensive school reform groups, charter networks, and high-capacity school districts embrace the standards aggressively, they might supply the educational infrastructure that would be needed to enable effective implementation of the standards.

\section{The Costs and Benefits of E-Reading} Gina Biancarosa and Gina Griffiths, both from the University of Oregon, sketch the landscape of "e-reading" today, pointing out that it takes place on a multitude of electronic devices and is rapidly increasing in popularity. This growth in e-reading has introduced new potential sources of economic and educational disparity in students' literacy outcomes. Nonetheless, exploiting the potential of e-reading designed in accordance with universal design principles and evidence-based instructional practices could support engagement as well as success for a wide variety of readers.

E-reading is increasingly used in schools, but there is relatively little information about programs that work well or about the valueadded of e-reading approaches to professional development or assessment. All these are 
areas that deserve greater attention, given the likely growth of investment by school districts in technology, the increased promotion of e-reading approaches by publishers, and the potential of e-reading to respond to the demands for differentiation of instruction, universal designs for learning, and rapidturnaround assessments.

\section{Rising to the Challenge}

The articles collected in this issue reinforce with data and analysis a growing recognition that policy makers, educators, and school systems have overemphasized technical reading skills and underemphasized conceptual knowledge and analytic skills in preparing students. This point has informed the call in the Common Core State Standards for more attention to informational text and analytical writing in instruction from kindergarten through twelfth grade, and these articles strongly support that shift. The dilemma these articles highlight, though, is that the domain of conceptual and analytical skills is very large and thus that support for development of such skills must be rich, consistent, and multipronged. Children from low-income and non-English-speaking families show poor performance on indexes of conceptual and analytical accomplishment at school entry, suggesting the importance of enhancing their access to better preschool experiences through programs that provide parental education, home-visiting services, and high-quality center-based care and education. Such children are likely to attend less-wellresourced schools, which underscores the importance of both improving instruction in the schools they attend and providing afterand out-of-school enrichment experiences for them. If such children's educators were the most knowledgeable and most linguistically sophisticated within the teaching corps, the children would more likely experience the kinds of learning environments they need.

Given the breadth of the challenge and the need for multiple points of entry in addressing it, we find it difficult to isolate a single solution or a particularly high-leverage approach. However, if limited to one, we would cite the impact in Finland and Singapore of improving the quality of classroom teachers by limiting access to the teaching profession to the top college graduates and by according teachers the high levels of respect due to professionals engaged in shaping the next generation. This is not a short-term plan, but it is the only one that has worked anywhere at a national scale, and it is almost certainly a prerequisite to the successful implementation of the Common Core State Standards. 


\section{Endnotes}

1. Frank Levy and Richard Murnane, The New Division of Labor (Princeton University Press, 2004).

2. Sean F. Reardon, "The Widening Academic Achievement Gap between the Rich and the Poor: New Evidence and Possible Explanations," in Whither Opportunity?, edited by Greg Duncan and Richard Murnane (New York: Russell Sage, 2011).

3. Jeff Diebold and others, "Policy Interventions to Promote Upward Mobility: Preliminary Results from the Social Genome Model,” Working paper (Washington: Brookings Institution, March 2012).

4. P. B. Gough and W. E. Tunmer, "Decoding, Reading, and Reading Disability," Remedial and Special Education 7 (1986): 6-10.

5. W. Kintsch, Comprehension: A Paradigm for Cognition (Cambridge University Press, 1998).

6. B. Hart and T. Risley, Meaningful Differences in the Everyday Experience of Young American Children (Baltimore: Brookes Publishing, 1995); M. Rowe and S. Goldin-Meadow, "Differences in Early Gesture Explain SES Disparities in Child Vocabulary Size at School Entry," Science 323 no. 5916 (2009): 951-53.

7. Greg Duncan and Richard Murnane, eds., Whither Opportunity? (New York: Russell Sage, 2011); D. K. Dickinson and M. V. Porche, "Relation between Language Experiences in Preschool Classrooms and Children's Kindergarten and Fourth-Grade Language and Reading Abilities," Child Development 82 (2011): 870-86.

8. R. A. Hoban, Best Friends for Frances (New York: HarperCollins, 1969), p. 1. 
